\title{
AN UNUSUAL CASE OF PENILE METASTASES FROM OSTEOSARCOMA OF FEMUR
}

Sushruth G. Kamoji1 ${ }^{1}$ S. Arunkumar², V. N. S. Ahamed Shariff ${ }^{3}$

\section{HOW TO CITE THIS ARTICLE:}

Sushruth G. Kamoji, S. Arunkumar, V. N. S. Ahamed Shariff. "An Unusual Case of Penile Metastases from Osteosarcoma of Femur". Journal of Evolution of Medical and Dental Sciences 2015; Vol. 4, Issue 04, January 12; Page: 707-710, DOI: 10.14260/jemds/2015/101

INTRODUCTION: The commonly seen genital ulcer disease has various etiologies and presentations of which malignancies constitute a minuscule proportion. Though primary malignancies of genitalia are not unusual, metastatic deposits in the penis is an extremely rare phenomenon. Here, we report a case of Osteosarcoma of femur presenting with secondaries in glans penis.

CASE REPORT: A 34 year old male, known case of Osteosarcoma of Right knee was referred from medical oncology with complaints of a genital ulcer of 3 months duration. The lesion had started as erosion over the tip of the penis and had gradually progressed in size. It was associated with minimal bleeding and pain on touch. It was not associated with purulent discharge or burning micturition. There was no history of oral ulcers, groin swellings, skin lesions joint pain, trauma or similar lesions in the past. Patient was married for the last 9 years and had 2 children. He denied having pre-marital or extra marital sexual contact. His last sexual contact with his wife was about 6 months back, and there was no history of genital lesions in his wife. Though patient was not a known diabetic or hypertensive he had an undeniably significant medical \& surgical history. In 2006, he had been diagnosed with Osteosarcoma of right femur (fig. 1 \& 2), and had undergone a limb salvage procedure with prosthetic implant and adjuvant chemotherapy. 2 years later he presented with local recurrence and lung metastases (confirmed by CT guided biopsy) for which he chose to undergo excision of only the locally recurrent lesion (Knee). A year later he presented with multiple unresectable lung metastases and migration of the prosthetic implant for which he underwent right hip disarticulation. 6 months later he presented to us with a genital ulcer. On local examination, patient was circumcised. There was a nodulo-ulcerative lesion of about $3 \times 2 \mathrm{cms}$ extending from the external urethral meatus with irregular borders and no visible discharge. On palpation the swelling was firm to hard in consistency, non-tender and did not have any discharge (fig. $3 \& 4$ ). Inguinal lymph nodes on both the sides were enlarged, discrete, firm, non-tender, non-fluctuant and 3 in number on either sides. There was no evidence of swelling or discharge at the amputation site. Systemic examination revealed scattered pulmonary crepts while per abdomen, cardiac and nervous system were normal. With thorough investigations we were able to rule out an infective etiology. Having done that, we subjected the patient to an edge-wedge biopsy which confirmed our speculation of metastatic deposits from the primary osteosarcoma (fig. 5 \& 6). His blood investigations revealed anemia and normal levels of alkaline phophatase and LDH. Having diagnosed a malignant condition, we referred the patient to medical oncology and urology for further management.

DISCUSSION: Despite being a highly vascular structure and having an extensive network of vascular communications, penis is a very unlikely site of metastases.(1) The earliest case of secondaries in the penis was reported by Eberth in 1870.(2) And when metastases do occur, they are mostly with 


\section{CASE REPORT}

primary of prostate, bladder or recto-sigmoid colon.(1)(3) Only a handful of cases have been reported from other sites such as kidney,(4) respiratory system(5) or bone.(6)(7) We would like to emphasize that till the year 2006 only 3 cases were reported with a primary malignancy of bone leading to metastases in the penis.(1)(3) A brief review of literature tells us that retrograde spread from venous plexus of pelvic viscera is the most common pathogenetic mechanism, apart from retrograde lymphatic spread, direct extension, arterial spread and implantation secondary to instrumentation.(8) The treatment options include surgery, chemotherapy, radiotherapy or hormonal therapy based on primary tumor and individual patients.(9) Neverthless, this condition has a very poor prognosis.(1) According to literature, cases of primary extraskeletal osteosarcoma ${ }^{(6)}$ and primary osteosarcoma in a heterotopic bone ${ }^{(7)}$ have been reported. The various differential diagnosis which may have to be considered are - chancroid, chancre, tuberculosis (infectious), peyronie's disease, factitious (benign), and malignancies like Bowen's disease, squamous cell carcinoma or verrucous carcinoma.

CONCLUSION: In the last 200 years only 3 cases have been reported with primary malignancy of bone leading to metastases in the penis. To the best of our knowledge this is the first case of Osteosarcoma presenting with secondaries in the penis. Even though malignancies of the genitalia are such a rare entity, one has to keep this in mind in patients diagnosed with a primary malignancy elsewhere in the body.

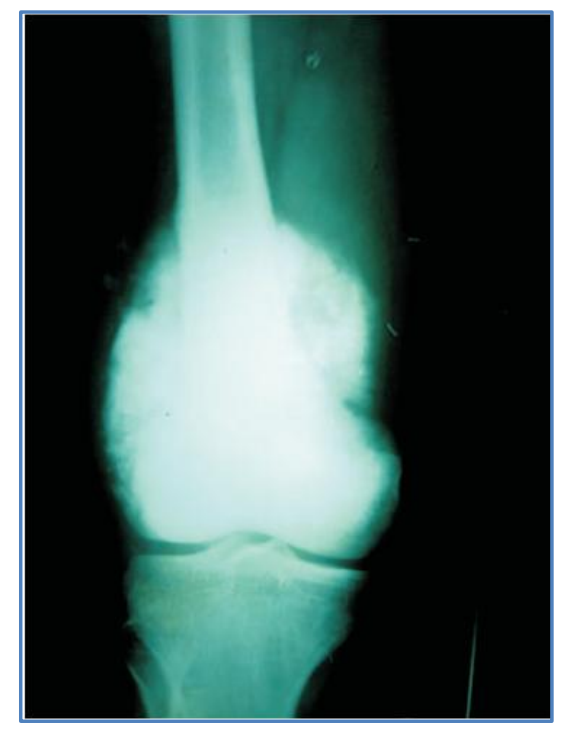

Fig. 1: Growth seen at lower end of right femur

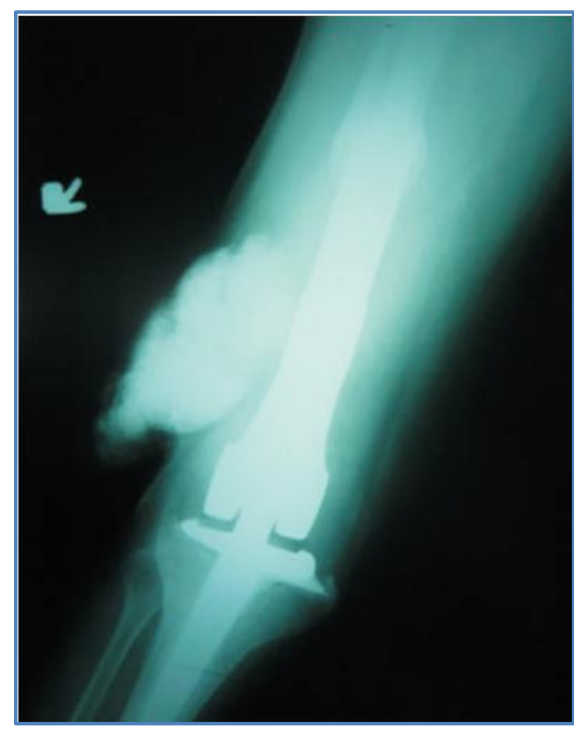

Fig. 2: Recurrence of lesion at site of primary resection; custom made knee prosthesis 


\section{CASE REPORT}

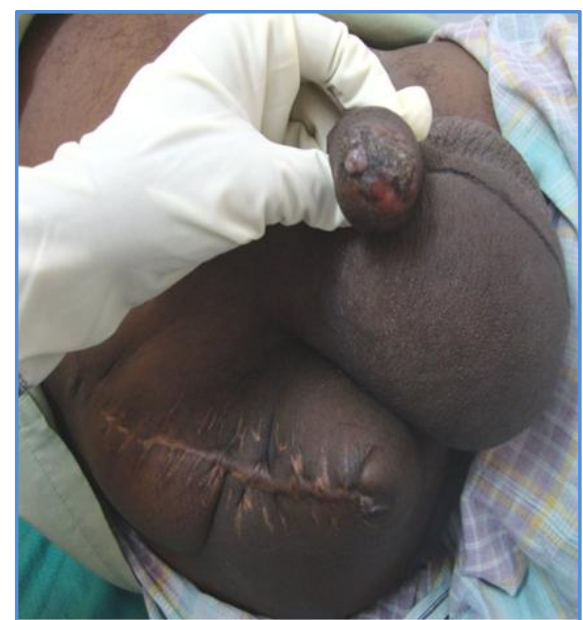

Fig. 3: Nodulo-ulcerative lesion with scar of right hip disarticulation

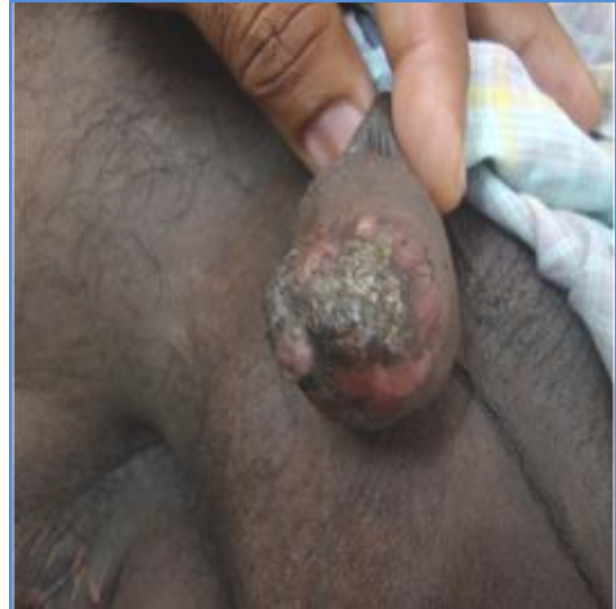

Fig. 4: Nodulo-ulcerative lesion with areas of crusting

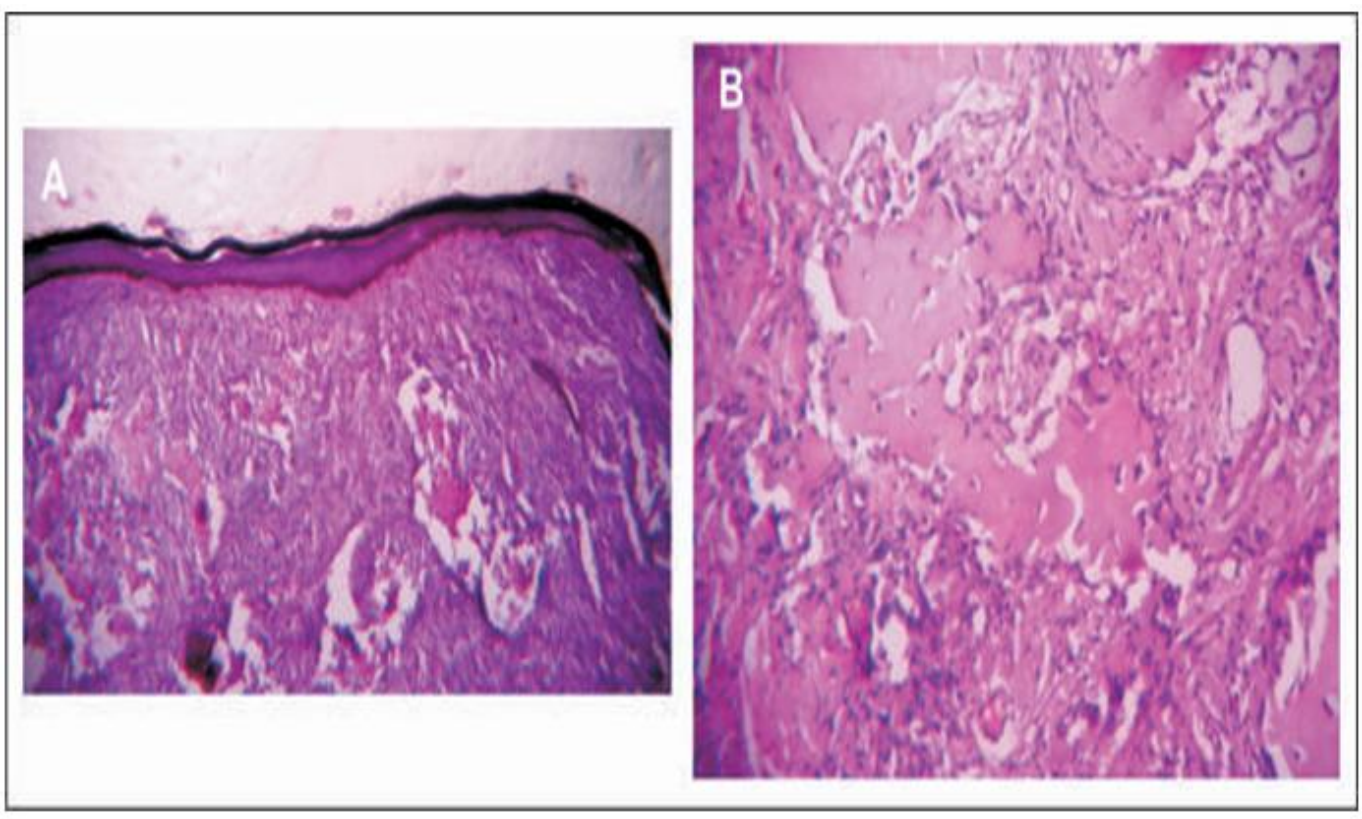

Fig. 5: Hemotoxylin- eosin stain of edge wedge biopsy of the penile lesion

A - low power

B - high power view showing osteoid deposition with scattered pleomorphic malignant cells.

\section{REFERENCES:}

1. Cherian J, Rajan S, Thwaini A, Elmasry Y, Shah T, and Puri R; Secondary penile tumours revisited; Int Semin Surg Oncol. 2006; 3: 33.

2. Eberth CJ. Krehsmetastasen des corpus cavernosum penis. Virch Arch. 1870; 51: 145. 


\section{CASE REPORT}

3. Perez LM, Shumway RA, Carson CC, Fisher SR, Hudson WR. Penile metastasis secondary to supraglottic squamous cell carcinoma: Review of the literature. J Urol. 1992; 147: 15.

4. Fallick ML, Long JP, Ucci A. Scandinavian Journal of Urology\& Nephrology; Metachronous renal cell carcinoma metastases to spermatic cord and penis; 1997 Jun; 31(3): 299-300.

5. Yokoi K, Miyazawa N, Muraki J, Nakazono M, Imura G, Shimamura K; Penile metastasis from lung cancer; Japanese Journal of Clinical Oncology. 1992 Aug; 22(4): 297-9.

6. P.J. BASTIAN, M.E. SCHMIDT, J. VOGEL*, G. STEINER, H.-P. BASTIAN and S.C. MÜLLER; Primary extraskeletal osteosarcoma of the glans penis and glanular reconstruction; BJU international 2007, vol 92 issue supplements.

7. Sacker AR, Oyama KK, Kessler S: Primary osteosarcoma of the penis. American Journal of Dermatopathology 1994; 16: 285-287.

8. Paquin AJ, Jr, Roland SI. Secondary carcinoma of the penis, A review of the literature and a report of nine new cases. Cancer. 1956; 9: 626.

9. Philip J, Mathew J; Penile metastasis of prostatic adenocarcinoma: Report of two cases and review of literature; World Journal of Surgical Oncology 2003, 1: 16.

\section{AUTHORS:}

1. Sushruth G. Kamoji

2. S. Arunkumar

3. V.N.S. Ahamed Shariff

\section{PARTICULARS OF CONTRIBUTORS:}

1. Resident, Department of Dermatology, Delgaum Institute of Medical Sciences, Belgaum.

2. Professor and Head, Department of Sexually Transmitted Diseases, Government Royapettah Hospital, Kilpauk Medical College, Chennai.

3. Senior Assistant Professor, Department of Dermatology, Madras Medical College, Chennai.

\section{NAME ADDRESS EMAIL ID OF THE CORRESPONDING AUTHOR:}

Dr. Sushruth G. Kamoji,

Flat 204, Doctors Quarters, Civil Hospital Campus, Opp. HDFC Bank, Belgaum - 590001.

E-mail: drsushruthk@yahoo.co.in

Date of Submission: 22/12/2015. Date of Peer Review: 23/12/2015. Date of Acceptance: 02/01/2015. Date of Publishing: 10/01/2015. 